\title{
EBV-associated lymphoproliferative disorder involving the gastrointestinal tract which mimic IBD in immunocompetent patients: case reports and literature review
}

\author{
Yanhua Zhou ${ }^{1} \cdot$ Yanlin Zhang ${ }^{2} \cdot$ Haiying Zhao ${ }^{1} \cdot$ Xuan Cui $^{3} \cdot$ Yongqiu Wei ${ }^{1} \cdot$ Yongdong Wu $^{1} \cdot$ Shutian Zhang ${ }^{1}$. \\ Ye Zong ${ }^{1}$
}

Accepted: 10 September 2019 / Published online: 23 October 2019

(C) The Author(s) 2019

\begin{abstract}
Introduction Epstein-Barr virus (EBV)-associated lymphoproliferative diseases (LPD) with digestive tract involvement in immunocompetent patients is rather rare. Since the symptoms of EBV-associated LPD involving the gastrointestinal tract in immunocompetent patients are similar to those of inflammatory bowel disease (IBD), most patients are initially misdiagnosed. Case presentation In this paper, we present two cases of EBV-associated T cell LPD involving the colon in immunocompetent patients and review the relevant literature.

Conclusion EBV serological testing may help in detecting this disease, and our findings suggest that histopathological evidence of EBV, such as the Epstein-Barr encoding region, is very important to establish the diagnosis.
\end{abstract}

Keywords Epstein-Barr virus infection $\cdot$ Lymphoproliferative disorder $\cdot$ Gastrointestinal tract $\cdot$ Diagnosis $\cdot$ Immunocompetent

\section{Introduction}

Epstein-Barr virus (EBV)-associated lymphoid diseases may present as EBV-related immunodeficiency [1] or nonimmunodeficiency diseases [2]. The latter manifest in various forms, including benign lymphoid tissue hyperplastic disorders, such as infectious mononucleosis; EBV-related lymphoma, such as Hodgkin's lymphoma, NK/T cell lymphoma, and Burkitt lymphoma [2]; and EBV-positive lymphoproliferative diseases (LPDs) [3, 4], which often show systemic manifestations, such as fever, organomegaly, and skin lesions. EBVassociated LPDs with digestive tract involvement in immunocompetent patients are rather rare, are often misdiagnosed

Ye Zong

zongye20171008@sina.com

Yanhua Zhou

zhouyanhuazyh@sina.com

1 Department of Gastroenterology, Beijing Friendship Hospital, Capital Medical University, Beijing 100050, China

2 Department of Pathology, Beijing Friendship Hospital, Capital Medical University, Beijing 100050, China

3 Department of Gastroenterology, People's Hospital of Dongcheng, Beijing, China during the initial stages, and its prognosis is very poor. In this paper, we present two cases of immunocompetent patients who developed EBV-associated T cell LPD involving the colon and also review the current literature on the topic.

\section{Case 1}

A previously healthy 44-year-old man presented with intermittent fever, abdominal pain, and bloody, mucoid bowel movements persisting for 3 months. The patient did not have any personal or family history of immunodeficiency. Physical examination revealed mild tenderness over the right lower abdominal quadrant. Laboratory tests revealed mild anemia (hemoglobin level, $11.9 \mathrm{~g} / \mathrm{dL}$ ), leukocytosis (white blood cell count, $17.1 \times 10^{9} / \mathrm{L}$ ) with a normal differential, elevated level of serum C-reactive protein (CRP, $98 \mathrm{mg} / \mathrm{dL}$ ), elevated erythrocyte sedimentation rate $(\mathrm{ESR}, 60 \mathrm{~mm} / \mathrm{h})$, moderate hypoalbuminemia (blood albumin level, $30 \mathrm{~g} / \mathrm{L}$; normal, $40-55 \mathrm{~g} / \mathrm{L}$ ), and normal globulin level. The results of the liver function tests were normal. T-SPOT® test was negative. Furthermore, the tests for human immunodeficiency virus, cytomegalovirus antibody IgM, and EBV antibody IgM were negative. Stool examination revealed the presence of a large number of red and white blood cells. However, stool culture, tests for Clostridium difficile toxins, and tests for stool parasites were 
negative. A computed tomography scan of the abdomen and pelvis revealed diffuse colonic thickening and normal appearance of the liver and spleen. Colonoscopy revealed the presence of multiple, intermittent deep ulcers across the entire length of the colon (Fig. 1a). Histological examination of the biopsy samples showed lymphoid and inflammatory hyperplasia of granulation tissues. The diagnosis was initially considered to be Crohn's disease, and accordingly, prednisone $(50 \mathrm{mg} /$ day $)$ and mesalazine $(4 \mathrm{~g} /$ day $)$ were administered. The treatment brought about a rapid improvement in the patient's symptoms, and the dosage of prednisone was quickly reduced. However, once the dose reached $30 \mathrm{mg} /$ day, there was a recurrence of fever and bloody stools. The patient was again admitted to our hospital. The results of the laboratory tests were as follows: leukocyte count, $6.7 \times 10^{9} / \mathrm{L}$; hemoglobin level, $10.0 \mathrm{~g} / \mathrm{dL}$; CRP level, $8 \mathrm{mg} / \mathrm{L}$; and ESR, $11 \mathrm{~mm} / \mathrm{h}$. We thought that the recurrence of fever was due to the rapid dose reduction of prednisone, and increased the dose to $50 \mathrm{mg} /$ day. This reduced the patient's fever and restored his bowel movement to normal, although the stool was still positive for occult blood. Colonoscopy was repeated, which revealed the presence of multiple, intermittent ulcers along the complete length of the colon, although the ulcers appeared to be less severe than before (Fig. 1b). Histological examinations of the biopsy samples revealed interstitial fibrous tissue hyperplasia, granulation tissue formation, and atypical lymphocyte cell infiltration (Fig. 2a). The samples subjected to immunohistochemical staining were positive for $\mathrm{CD} 3$ and $\mathrm{CD} 5$, but negative for CD56. Many of the atypical cells were positive for Epstein-Barr encoding region (EBER) in situ hybridization (Fig. 2b). Although the EBV-CA-IgM of serum was normal, serum EBV DNA level was $5.3 \times 10^{3}$ copies $/ \mathrm{mL}$. On the basis of these tests, EBV + T-LPD with colonic involvement was diagnosed. The patient was then treated with DEP (doxorubicin, etoposide, and methylprednisolone) chemotherapy regimen, with a gradual reduction in prednisone dosage. After the second chemotherapy cycle, the patient developed severe fungal pneumonia. Therefore, chemotherapy was discontinued. During the 18-month follow-up period, the patient remained asymptomatic and did not require any medicine.

\section{Case 2}

A previously healthy 48 -year-old man presented with diarrhea and abdominal pain persisting for one and a half years. Colonoscopy revealed multiple, diffuse, deep ulcers along the right colon. Under the diagnosis of Crohn's disease, the patient was treated with and hydrocortisone $(100 \mathrm{mg} /$ day $)$ for 8 days. A marked improvement in the symptoms was noted, and the dosage of hydrocortisone was gradually reduced. Eight months after the initiation of treatment, the patient underwent a repeated colonoscopy in our hospital to evaluate the status of the disease. Colonoscopy revealed that deep ulcers in the ileocecal valve and ascending colon persisted (Fig. 3). Laboratory tests revealed the following: leukocyte count, $5.8 \times 10^{9} / \mathrm{L}$; hemoglobin level, $11.7 \mathrm{~g} / \mathrm{dL}$; CRP level, $21 \mathrm{mg} / \mathrm{L}$; ESR, $26 \mathrm{~mm} / \mathrm{h}$; mild hypoalbuminemia, $(38.4 \mathrm{~g} / \mathrm{L})$; and normal globulin level. Furthermore, stool occult blood, stool culture, tests for stool parasites, and tests for Clostridium difficile toxins were all negative. In addition, TSPOT ${ }^{\circledR}$ test was negative. Moreover, tests for the detection of human immunodeficiency virus, cytomegalovirus antibody CMVAb-IgM, and EBVAb-IgM were negative. Serum EBV DNA level was $8.6 \times 10^{3}$ copies $/ \mathrm{mL}$. Abdomen and pelvis computed tomography scans showed ileocecal intestinal thickening. Histological examinations of the biopsy samples of the colon showed the abundant infiltration of slightly atypical lymphocyte cells. Immunohistochemical staining showed that cells were positive for $\mathrm{CD} 3$, partially positive for $\mathrm{CD} 5$, and negative for CD56. Many of the atypical cells were positive for EBER in situ hybridization. On the basis of these findings, the diagnosis was established as EBV + T-LPD with colonic involvement. Since the patient was asymptomatic, chemotherapy was not initiated. Four months after being discharged from our hospital, the patient developed high fever. He was admitted to another hospital and died 2 weeks later.
Fig. 1 Endoscopic images of case 1. a Initial colonoscopy. Colonoscopy revealed the presence of multiple diffuse deep ulcers across the entire colon. $\mathbf{b}$ Repeat colonoscopy. After more than 20 days of treatment with prednisone, the second colonoscopy also revealed multiple, intermittent ulcers throughout the colon, but the ulcers were less severe than before

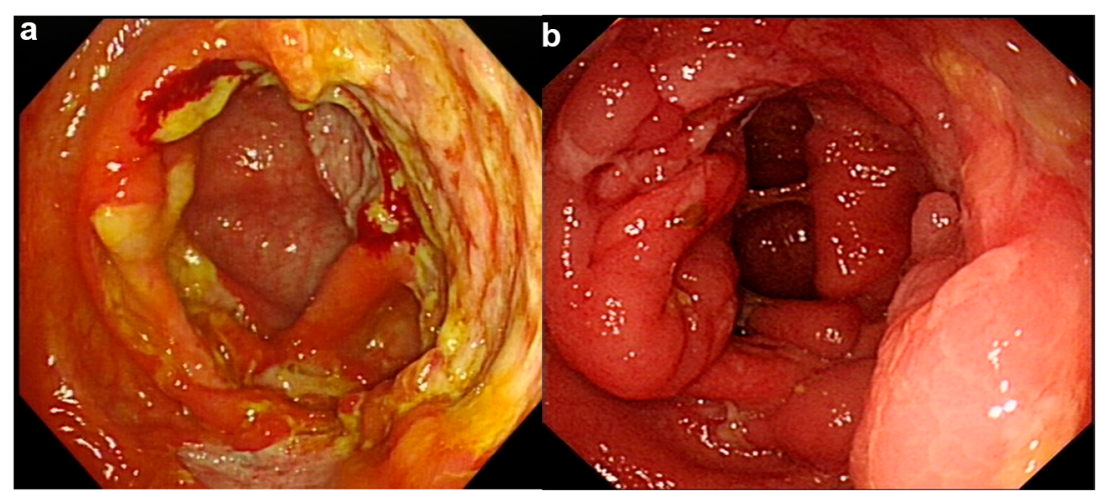


Fig. 2 Pathological results of case 1. a Histological examination of the biopsy samples: The samples revealed the abundance of atypical lymphocyte cells. b Immunohistochemical examination: A number of atypical cells were positive for EBER in situ hybridization

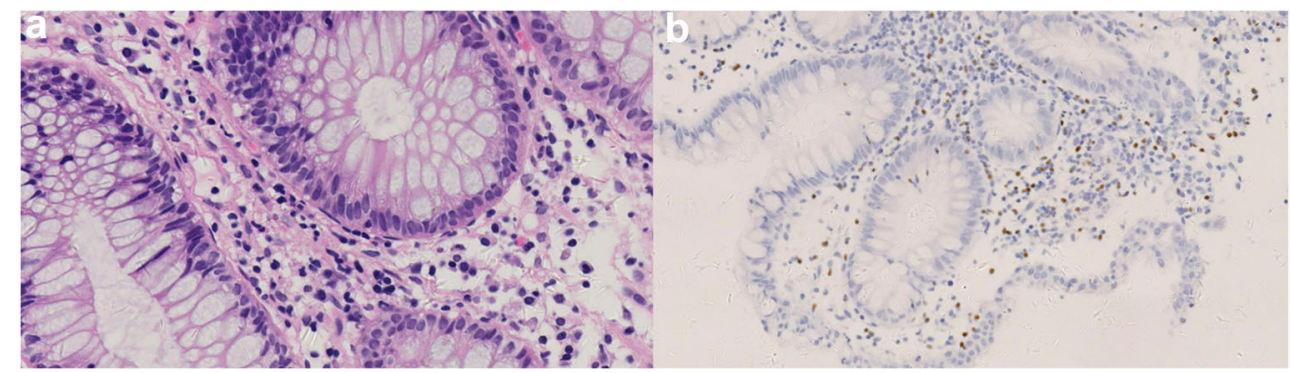

\section{Discussion}

EBV-associated LPD is defined as EBV + B cell LPD or EBV $+\mathrm{T} / \mathrm{NK}$ cell LPD according to the World Health Organization's classification system, and encompasses disease entities with a broad clinicopathologic spectrum [5]. EBV-associated LPD is usually observed in patients with congenital or acquired immunodeficiency $[6,7]$, and the organs most commonly involved are the liver, spleen, bone marrow, skin, and lymph nodes [8]. EBV-associated LPD with digestive tract involvement in immunocompetent patients is rather rare and is often misdiagnosed; therefore, the diagnosis of these entities is often challenging.

Although many reports have been published on EBVassociated LPD, cases of gastrointestinal involvement and description in immunocompetent patients are rather rare. A total of 15 cases (including two of our own) have been reported [9-19]: two cases of B cell type LPD [9, 10], 12 cases of T/ NK-cell type LPD [11-19], and one case of an unknown cell type [13].

The parts of the gastrointestinal tract involved were the esophagus (1/15), stomach (1/15), duodenum (1/15), small bowel (5/15), and colon (12/15), with the colon being the most common site involved. Fever and diarrhea were the most common symptoms, occurring in $80.0 \%$ of the patients $(12 / 15)$. Other symptoms included hematochezia (7/15), abdominal

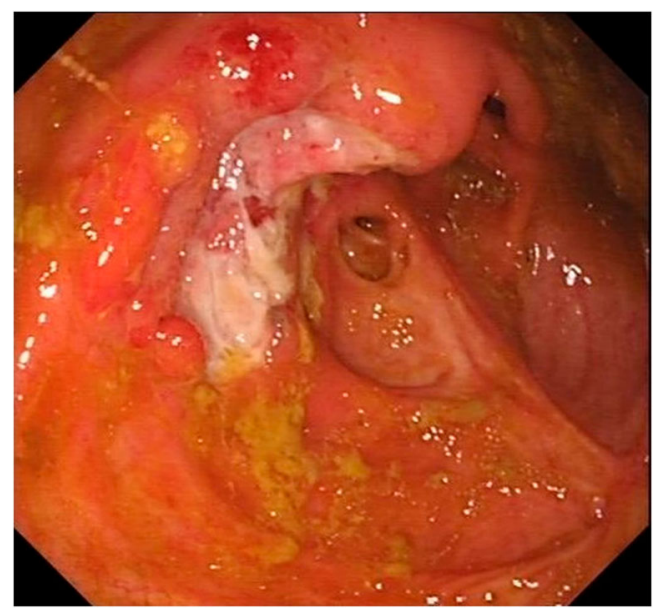

Fig. 3 Case 2: Colonoscopy. Colonoscopy revealed deep ulcers in the ileocecal valve and ascending colon after hydrocortisone treatment pain $(7 / 15)$, melena $(2 / 15)$, weight loss $(3 / 15)$, bloody mucoid bowel movements $(2 / 15)$, and skin nodules (1/15). Because the symptoms of EBV-associated LPD involving the gastrointestinal tract in immunocompetent patients were remarkably similar to those of inflammatory bowel disease (IBD), most cases were initially misdiagnosed as IBD. Although this disease is rare, it should be taken into consideration in the differential diagnosis of IBD.

The laboratory tests results for these reported cases revealed leukocytosis (6/15), a mild decrease in leukocyte expression (1/15), or severe pancytopenia (1/15). The results of the liver function tests were abnormal in five patients. Tests for the detection of EBV in blood were not performed in all the above-mentioned cases, and abnormal levels of anti-EBV antibodies were not observed in all patients, although EBV-DNA levels were elevated in four patients. For the latter patients, initial laboratory tests did not yield any specific findings, and EBV-DNA measurement was more helpful for the diagnosis than the other tests. Kimura et al. [20] reported a cases series of 30 patients with chronic EBV infection. While all their patients did not exhibit high titers of EBV-specific antibodies, all of them did have elevated levels of EBV DNA copies in peripheral blood samples. Similarly, Suzuk et al. [21] reported that serologic titers of EBV were only modestly elevated or not elevated in 43 patients with EBV-T/NK-LPD.

The diagnosis of EBV-associated LPD is dependent on the histological findings. EBV and EBV-infected cells generally exhibit polyclonal and oligoclonal proliferation to monoclonal proliferation. Therefore, it may be a spectrum encompassing benign, borderline, and malignant lesions [4]. Detection of EBER-positive cells in affected tissues is very important for establishing the diagnosis of EBV-associated LPD.

In seven of the 15 cases reported to date, the diagnosis was initially considered to be IBD before EBV-associated LPD was confirmed. This is due to the marked similarity of the symptoms and clinical manifestations between IBD and EBV-associated LPD involving gastrointestinal tract in immunocompetent patients. Therefore, in practice, we should check for EBV-LPD in patients diagnosed with IBD. Some of the differences between the clinical presentations of IBD and EBV-LPD with gastrointestinal tract involvement are as follows: (1) Fever, especially inexplicable high fever, is more common in patients with EBV-LPD. In patients with 
suspected IBD, if there is a high fever that is not consistent with the other symptoms of the patient and there is no infection, other diseases should be considered, including EBVLPD [11]. (2) Involvement of other organ systems, such as the enlargement of the liver, spleen, and lymph nodes, is common in the patients with EBV-LPD. If the lesions are only located in the gastrointestinal tract in EBV-LPD, the differential diagnosis is very difficult. However, once the disease progresses, other systems may also be affected. Therefore, even if the diagnosis of IBD may be established initially, clinicians should monitor their patients for any changes in clinical manifestations. Unlike the case with EBV-LPD, some patients with IBD may also present with extraintestinal manifestations such as primary sclerosing cholangitis, fatty liver, cholelithiasis, and IgG4-related cholangitis [22]. (3) Although all patients with EBV-LPD do not test positive in EBV blood tests, tests for EBV-DNA, VCA-IgG, and EA-IgG would be useful in the differential diagnosis of EBV-LPD. (4) Histopathological examination is crucial for the diagnosis. We recommend that for patients with suspected IBD, EBER test for tissues obtained from the digestive tract should be performed.

Nonetheless, it should be noted that immunosuppressive therapy in patients with IBD, especially Crohn's disease, may induce EBV-associated LPD. Laurent et al. [23] assessed the risk of lymphoproliferative disorders in patients treated with thiopurines and found that the hazard ratio for LPD among these patients was 5.28. Sokol et al. [24] also reported that patients with IBD have an increased risk of developing primary intestinal lymphoproliferative disorders. Therefore, regular monitoring with blood tests and histological examination of intestinal histology is important for patients with IBD [25].

Currently, there is no specific treatment for the condition. Glucocorticoids have been shown to partially relieve the initial symptoms, which also mimic IBD among some patients $[11,17]$. However, the prognosis of this disease is very poor. The majority (9/15) of the reported cases of EBV-associated LPD ended in fatality.

\section{Conclusion}

In conclusion, EBV-associated LPD with digestive tract involvement in immunocompetent patients is rare and easily misdiagnosed. Therefore, in patients with similar presentations, clinicians should carefully monitor the changes in the symptomatology and perform EBV serological testing for EBV-DNA, VCA-IgG, and EA-IgG as well as histopathological examination for evidence of EBV such as EBER, in order to facilitate the diagnosis.
Authors' contributions Yanhua Zhou and Ye Zong performed most of the investigation, data analysis, and wrote the manuscript; Yanlin Zhang provided pathological assistance; Haiying Zhao, Xuan Cui, and Yongqiu Wei contributed to case collection; And Yongdong $\mathrm{Wu}$ and Shutian Zhang revised the paper. All of the authors have read and approved the manuscript.

Data availability The datasets generated and analyzed during the present study are available from the corresponding author on reasonable request.

\section{Compliance with ethical standards}

Conflict of interest The authors declare that they have no conflict of interest.

Research involving human participants and/or animals This study was approved by the ethics committee of Beijing Friendship Hospital, Capital Medical University. All procedures performed in studies involving human participants were in accordance with the ethical standards of the institutional and/or national research committee and with the 1964 Helsinki declaration and its later amendments or comparable ethical standards.

Informed consent All data published here are under the consent for publication. Written informed consent was obtained from all individual participants included in the study.

Open Access This article is distributed under the terms of the Creative Commons Attribution 4.0 International License (http:// creativecommons.org/licenses/by/4.0/), which permits unrestricted use, distribution, and reproduction in any medium, provided you give appropriate credit to the original author(s) and the source, provide a link to the Creative Commons license, and indicate if changes were made.

\section{References}

1. Hatachi S, Kunitomi A, Aozasa K, Yagita M (2010) CD8(+) T-cell lymphoproliferative disorder associated with Epstein-Barr virus in a patient with rheumatoid arthritis during methotrexate therapy. Mod Rheumatol 20:500-505. https://doi.org/10.1007/s10165-010-0300$\mathrm{z}$

2. Swerdlow SH, Campo E, Harris NL, Jaff ES, Pileri S, Stein H, Thele J, Vardiman JW (2016) WHO classifcation of tumours of haematopoietic and lymphoid tissues. IARC, Lyon

3. Cohen JI, Kimura H, Nakamura S, Ko YH, Jaffe ES (2009) Epstein-Barr virus-associated lymphoproliferative disease in nonimmunocompromised hosts: a status report and summary of an international meeting, 8-9 September 2008. Ann Oncol 20:14721482. https://doi.org/10.1093/annonc/mdp064

4. Ohshima K, Kimura H, Yoshino T, Kim CW, Ko YH, Lee SS, Peh SC, Chan JK, Group CS (2008) Proposed categorization of pathological states of EBV-associated T/natural killer-cell lymphoproliferative disorder (LPD) in children and young adults: overlap with chronic active EBV infection and infantile fulminant EBV T-LPD. Pathol Int 58:209-217. https://doi.org/10.1111/j.1440-1827.2008. 02213.x

5. Kim HJ, Ko YH, Kim JE, Lee SS, Lee H, Park G, Paik JH, Cha HJ, Choi YD, Han JH, Huh J, Hematopathology Study Group of the Korean Society of P (2017) Epstein-Barr virus-associated 
lymphoproliferative disorders: review and update on 2016 WHO classification. J Pathol Transl Med 51:352-358. https://doi.org/10. 4132/jptm.2017.03.15

6. Sanz J, Andreu R (2014) Epstein-Barr virus-associated posttransplant lymphoproliferative disorder after allogeneic stem cell transplantation. Curr Opin Oncol 26:677-683. https://doi.org/ 10.1097/CCO.0000000000000119

7. Yang X, Nishida N, Zhao X, Kanegane H (2015) Advances in understanding the pathogenesis of Epstein-Barr virus-associated lymphoproliferative disorders. Iran J Allergy Asthma Immunol 14:462-471

8. Wang RC, Chang ST, Hsieh YC, Huang WT, Hsu JD, Tseng CE, Wang MC, Hwang WS, Wang J, Chuang SS (2014) Spectrum of Epstein-Barr virus-associated T-cell lymphoproliferative disorder in adolescents and young adults in Taiwan. Int J Clin Exp Pathol 7: 2430-2437

9. Karlitz JJ, Li ST, Holman RP, Rice MC (2011) EBV-associated colitis mimicking IBD in an immunocompetent individual. Nat Rev Gastroenterol Hepatol 8:50-54. https://doi.org/10.1038/ nrgastro.2010.192

10. Oosterveld M, Lesterhuis WJ, MacKenzie M, van Krieken JH (2003) EBV-related lymphoproliferative disorders in immunocompetent patients. Leukemia 17:2537-2538. https://oi.org/10.1038/ sj.leu. 2403155

11. Chen H, Zhang Y, Jiang Z, Zhou W, Cao Q (2016) A case report of NK-cell lymphoproliferative disease with a wide involvement of digestive tract develop into Epstein-Barr virus associated NK/T cell lymphoma in an immunocompetent patient. Medicine (Baltimore) 95:e3176. https://doi.org/10.1097/MD.0000000000003176

12. Clayton RA, Malcomson RD, Gilmour HM, Crawford DH, Parks RW (2005) Profuse gastrointestinal haemorrhage due to delayed primary Epstein-Barr virus infection in an immunocompetent adult. Histopathology 47:439-441. https://doi.org/10.1111/j.1365-2559. 2005.02130.x

13. Lavin AC, Roman JG, Zarate SA, Porras MC, Caviedes JR (2009) Acute upper gastrointestinal bleeding associated with Epstein-Barr virus reactivation in an immunocompetent patient. Am J Gastroenterol 104:253-254. https://doi.org/10.1038/ajg.2008.25

14. Na HK, Ye BD, Yang SK, Yang DH, Jung KW, Kim KJ, Byeon JS, Myung SJ, Huh J, Kim JH (2013) EBV-associated lymphoproliferative disorders misdiagnosed as Crohn's disease. J Crohns Colitis 7: 649-652. https://doi.org/10.1016/j.crohns.2012.09.018

15. Sazuka S, Takahashi Y, Kawaguchi T, Sato T, Nakagawa T, Furuya Y, Saito M, Saito K, Katsuno T, Nakaseko C, Yokosuka O (2012) Endoscopic findings of small-intestinal Epstein-Barr virusassociated T-cell lymphoproliferative disorder. Endoscopy 44 Suppl 2 UCTN:E30-1. https://doi.org/10.1055/s-0030-1257081

16. Shen K, Chen XC, Liu T (2013) Intestinal lesions as the primary clinical manifestation of adult-onset systemic Epstein-Barr virus positive T-cell lymphoproliferative disease. West China Med J 28: 840-843

17. Xiao HJ, Li J, Song HM, Li ZH, Dong M, Zhou XG (2016) Epstein-Barr virus-positive T/NK-cell lymphoproliferative disorders manifested as gastrointestinal perforations and skin lesions: a case report. Medicine (Baltimore) 95:e2676. https://doi.org/10. 1097/MD.0000000000002676

18. Zheng X, Xie J, Zhou X (2015) Epstein-Barr virus associated T-cell lymphoproliferative disease misdiagnosed as ulcerative colitis: a case report. Int J Clin Exp Pathol 8:8598-8602

19. Abdul-Ghafar J, Kim JW, Park KH, Cho MY (2011) Fulminant Epstein-Barr virus-associated T-cell lymphoproliferative disorder in an immunocompetent middle-aged man presenting with chronic diarrhea and gastrointestinal bleeding. J Korean Med Sci 26:11031107. https://doi.org/10.3346/jkms.2011.26.8.1103

20. Kimura H, Hoshino Y, Kanegane H, Tsuge I, Okamura T, Kawa K, Morishima T (2001) Clinical and virologic characteristics of chronic active Epstein-Barr virus infection. Blood 98:280-286

21. Suzuki K, Ohshima K, Karube K, Suzumiya J, Ohga S, Ishihara S, Tamura K, Kikuchi M (2004) Clinicopathological states of EpsteinBarr virus-associated T/NK-cell lymphoproliferative disorders (severe chronic active EBV infection) of children and young adults. Int J Oncol 24:1165-1174

22. Gizard E, Ford AC, Bronowicki JP, Peyrin-Biroulet L (2014) Systematic review: the epidemiology of the hepatobiliary manifestations in patients with inflammatory bowel disease. Aliment Pharmacol Ther 40:3-15. https://doi.org/10.1111/apt.12794

23. Beaugerie L, Brousse N, Bouvier AM, Colombel JF, Lemann M, Cosnes J, Hebuterne X, Cortot A, Bouhnik Y, Gendre JP, Simon T, Maynadie M, Hermine O, Faivre J, Carrat F, Group CS (2009) Lymphoproliferative disorders in patients receiving thiopurines for inflammatory bowel disease: a prospective observational cohort study. Lancet 374:1617-1625. https://doi.org/10.1016/S01406736(09)61302-7

24. Sokol H, Beaugerie L, Maynadie M, Laharie D, Dupas JL, Flourie B, Lerebours E, Peyrin-Biroulet L, Allez M, Simon T, Carrat F, Brousse N, Group CS (2012) Excess primary intestinal lymphoproliferative disorders in patients with inflammatory bowel disease. Inflamm Bowel Dis 18:2063-2071. https://doi.org/10.1002/ibd. 22889

25. Lam GY, Halloran BP, Peters AC, Fedorak RN (2015) Lymphoproliferative disorders in inflammatory bowel disease patients on immunosuppression: lessons from other inflammatory disorders. World J Gastrointest Pathophysiol 6:181-192. https:// doi.org/10.4291/wjgp.v6.i4.181

Publisher's note Springer Nature remains neutral with regard to jurisdictional claims in published maps and institutional affiliations. 